\title{
Cumulative effect of reproductive factors on ideal cardiovascular health in postmenopausal women: a cross-sectional study in central south China
}

\author{
Xia Cao ${ }^{1}$, Jiansong Zhou' ${ }^{2}$ Hong Yuan ${ }^{3}$ and Zhiheng Chen ${ }^{1 *}$
}

\begin{abstract}
Background: The American Heart Association developed the Life's Simple 7 metric for defining cardiovascular health. Little is known, however, whether co-occurring reproductive factors, which affects endogenous oestrogen levels during a woman's life, also influences ideal cardiovascular health in postmenopausal women.

Methods: Using data on a cross-sectional study with a convenience sample of 1,625 postmenopausal women (median age, 60.0 years) in a medical health checkup program at a general hospital in central south China 2013-2014, we examined the association between cumulative reproductive risk and ideal cardiovascular health in postmenopausal women. A cumulative risk score (range 0 to 4 ) was created by summing four reproductive risk factors (age at menarche, age at menopause, number of children, and pregnancy losses) present in each individual from binary variables in which 0 stands for favorable and 1 for less-than-favorable level. Ideal levels for each component in Life's Simple 7 (blood pressure, cholesterol, glucose, BMI, smoking, physical activity, and diet) were used to create an ideal Life's Simple 7 score [0-1 (low), 2, 3, 4, 5 and 6-7 (high)].

Results: Participants with earlier age at menarche (odds ratio [OR] $=0.42$ [95 \% Cl 0.26-0.48]), earlier age at menopause [0.46 (0.32-0.58)], who have more than three children (0.42 [0.38-0.56]) and have history of pregnancy losses [0.76 (0.66-0.92)] were more likely to attain low (0-1) ideal Life's Simple 7 after adjustment for age. Participants were more likely to attain low (0-1) ideal Life's Simple 7 as exposure to the number of reproductive risk factors increased [OR $(95 \% \mathrm{Cl})$ of $0.52(0.42-0.66), 0.22(0.16-0.26)$, and $0.16(0.12-0.22)$ for cumulative reproductive risk scores of 1 , 2 , and 3 or 4 , respectively, each versus 0$]$.
\end{abstract}

Conclusions: The postmenopausal Chinese women with an increasing number of reproductive risk factors were progressively less likely to attain ideal levels of cardiovascular health factors.

Keywords: Cardiovascular health, Reproductive risk, Menopause, Chinese women

\section{Background}

The American Heart Association (AHA) has defined the construct of "ideal cardiovascular health" based on 7 cardiovascular health metrics to measure progress toward their 2020 Impact Goal [1]. A substantial body of evidence demonstrates that the ideal cardiovascular

\footnotetext{
* Correspondence: cx_csu@163.com

'Department of Health Management Center, the Third Xiangya Hospital, Central South University, Tongzipo Road 138, Changsha, Hunan Province 410013, China

Full list of author information is available at the end of the article
}

health index is associated with reduced cardiovascular morbidity and mortality $[2,3]$.

Known as the "change of life", menopause is one of the important stages of a woman's life with the loss of ovarian function and reproductive determinants of health have essentially formed in this stage. It is well known that postmenopausal women have a high risk of developing cardiovascular disease $[4,5]$. However, the postmenopausal women possibly still benefit from the endogenous oestrogen produced during their reproductive history, due to the effects it exerted on conventional 
cardiovascular risk factors [6]. Among female reproductive factors, early menarche and early menopause have been identified to be associated with the risk of mortality from cardiovascular disease in postmenopausal women [7-9]. Nevertheless, there remains less knowledge on whether reproductive factors, developing during a woman's reproductive span, would have a protective role in good cardiovascular health after menopause. Moreover, so far, studies examining the relationship between reproductive factors and cardiovascular risk factors have seldom explored their cumulative effect, that is whether exposure to multiple reproductive factors at the same time might influence the favorable cardiovascular health profile.

Accordingly, the aim of the present study was to explore the association between cumulative reproductive risk and ideal cardiovascular health using data from a sample of urban postmenopausal women in central south China who participated in the 2013-2014 Changsha Women's Health Screening Program (CSWHSP).

\section{Methods}

\section{Study participants}

CSWHSP is a follow-up study assessing risk factors underlying women's reproductive and cardio-metabolic diseases sponsored by Changsha Labor and Social Security Bureau started in 2011. Participants of the present study were 1,927 community postmenopausal female residents who entered this program during 2013 to 2014 conducted by the health management center of Third Xiangya Hospital of Central South University. Menopausal status was determined by self-reported menstrual cycle characteristics. Postmenopausal women had gone 1 year or longer without menses according to STRAW criteria as well [10]. We excluded participants from the study who had prevalent cardiovascular diseases (defined as a selfreported history of stroke, myocardial infarction or heart failure). Moreover, those who had missing data for one or more of the anthropometric variables under study were also excluded. Therefore, the final analysis set consisted of a total of 1,625 participants. The study followed the standards of the Declaration of Helsinki and has been approved by the Institutional Review Board of the Third Xiangya Hospital, Central South University. As the dataset used in this study is consisted of de-identified data from a retrospective cohort, the written informed consents from the participants who receiving physical check-up were waived by the approval of the IRB.

\section{Data collection}

\section{Reproductive risk factors}

We assessed 4 reproductive factors that have been proposed as mainly components of female reproductive history in previous literature [6, 7]. The four reproductive factors of interest was self-reported through the questionnaire and included age at menarche, age at menopause, number of children, and pregnancy losses. We created a sum of the reproductive risk factors present in each individual from binary variables in which 0 stands for favorable and 1 for less-thanfavorable level. The cut-off points were based on previous evidence and theoretical knowledge. Earlier age at menarche was defined as starting menarche at an age $<12$ years [11]. Earlier age at menopause was defined as either natural menopause or surgical removal of ovaries at an age $<46$ years [12]. High parity was defined as the number of times a woman has borne children $\geq 3$ [13]. Pregnancy losses were defined as having history of miscarriage, abortion or stillbirth [14].

\section{Ideal cardiovascular health index}

The ideal cardiovascular health index comprised 7 ideal metrics was adapted from the AHA metric [1]. Each metric of cardiovascular health including cigarette smoking, body mass index (BMI), physical activity, diet, total cholesterol (TC), blood pressure (BP), and fasting blood glucose (FBG) were classified into three levels (poor $=1$ points; intermediate $=2$ point; ideal $=3$ points; total score: $7-21$ points) . Cigarette smoking status, physical activity, and diet were self-reported through the questionnaire collected in person by trained doctors. Trained staff reviewed the completed questionnaires and entered the responses into a database.

Detailed definitions of "poor", "intermediate", and "ideal" levels for all seven metrics are given below. Cigarette smoking: ideal, never smoker; intermediate, smoking cessation; poor, current smoker. BMI: ideal, $<25 \mathrm{~kg} / \mathrm{m}^{2}$; intermediate, $25-30 \mathrm{~kg} / \mathrm{m}^{2}$; poor, $\geq 30 \mathrm{~kg} / \mathrm{m}^{2}$. We had insufficient information about physical activity and dietary intake. Physical activity was assessed using the questionnaire that assesses the frequency and duration of participation in moderate and vigorous physical activity during the past 30 days. Physical activity: ideal, $\geq 90 \mathrm{~min} /$ week; intermediate, 0-89 $\mathrm{min} /$ week; poor, never exercise. Ideal diet included following 4 components: $\geq 450 \mathrm{~g} / \mathrm{d}$ fruits or vegetables, $\geq 2$ servings of fish per week, 3 or more 1-oz servings a day of whole grains, and sodium < $1500 \mathrm{mg} / \mathrm{d}$. Diet categories were as follows: ideal, having $\geq$ 3 ideal diet components of the above 4 components; intermediate, having 1-2 ideal diet components; poor, having none ideal diet components. TC: ideal, untreated $\mathrm{TC}<$ $5.17 \mathrm{mmol} / \mathrm{L}$; intermediate, untreated TC $5.18-6.19 \mathrm{mmol} /$ $\mathrm{L}$ or treated $\mathrm{TC}<5.17 \mathrm{mmol} / \mathrm{L}$; poor, $\mathrm{TC} \geq 6.20 \mathrm{mmol} / \mathrm{L}$. BP: ideal, untreated systolic BP (SBP) $<120 \mathrm{mmHg}$ and diastolic $\mathrm{BP} \quad(\mathrm{DBP})<80 \mathrm{mmHg}$; intermediate, SBP $120-139 \mathrm{mmHg}$ or DBP $80-89 \mathrm{mmHg}$ or treated $\mathrm{BP}<$ $120 / 80 \mathrm{mmHg}$; poor: $\mathrm{SBP} \geq 140 \mathrm{mmHg}$ or $\mathrm{DBP} \geq$ $90 \mathrm{mmHg}$. FBG: ideal, untreated $\mathrm{FBG}<5.6 \mathrm{mmol} / \mathrm{L}$; intermediate, FBG 5.6-6.9 mmol/L or treated $\mathrm{FBG}<$ 
$5.6 \mathrm{mmol} / \mathrm{L}$; poor, $\mathrm{FBG} \geq 7.0 \mathrm{mmol} / \mathrm{L}$. Current use of medications was based on self-report.

\section{Clinical measurement of cardiovascular risk factors}

All examinations were done at Third Xiangya Hospital of Central South University. Body weight and height were measured by a balance scale, with the participant standing erect, arms at her side and feet together. Weight was measured to the nearest $0.1 \mathrm{~kg}$. Height was measured to the nearest $0.5 \mathrm{~cm}$. Body mass index $\left(\mathrm{BMI}, \mathrm{kg} / \mathrm{m}^{2}\right)$ was defined as the weight in kilograms divided by the square of the height in meters. Three blood pressure readings were taken after a quiet rest in a sitting position for $5 \mathrm{~min}$, with the average used for data analysis.

Blood samples were drawn from the antecubital vein by careful venipuncture using a 21-G sterile syringe without stasis at 08:00-10:00 hours after a fasting period of $12 \mathrm{~h}$ and analyzed using standard protocols. Concentrations of fasting blood glucose (FBG), total cholesterol (TC), and triglycerides (TG) were determined by enzymatic colorimetric assay.

\section{Statistical analyses}

Statistics analysis was calculated using SPSS statistical software package version 19.0 (SPSS Inc., Chicago, IL, USA). Age- adjusted odds ratios (ORs) and $95 \%$ confidence intervals (CIs) of each of Life's Simple 7 component (poor, intermediate, and ideal) were calculated for each reproductive risk factor (earlier age at menarche, earlier age at menopause, more than three children, and pregnancy losses) using multinomial logistic regression. Multinomial logistic regression was used to estimate age- adjusted ORs and $95 \%$ CIs for the associations between individual reproductive risk factors and ideal Life's Simple 7 scores $(2,3,4$, 5 , and 6-7 versus $0-1)$. Age- adjusted odds ratios and $95 \%$ CIs for higher ideal Life's Simple 7 scores (2, 3, 4, 5, and $6-7$ versus $0-1$ ) by cumulative reproductive risk score $(1,2$, and 3 or 4 each versus 0$)$ were also estimated using multinomial logistic regression. We hypothesized the cumulative reproductive risk score was associated with ideal Life's Simple 7 scores independent of each individual reproductive risk factor. To test it, we constructed models that included a continuous variable for cumulative reproductive risk score and each individual reproductive risk factor, and assessed whether the variable for cumulative reproductive risk remained statistically significant. Statistical significance was considered at $P<0.05$ and all tests were two-sided.

\section{Results}

A total of 1,927 postmenopausal women participated in the 2013-2014 CSWHSP, from whom 302 were excluded: 48 with history of stroke, 76 with history of myocardial infarction, 2 with history of both stroke and myocardial infarction, and 81 lacking information regarding the seven metrics. We further excluded participants with missing data on the age at menarche $(n=67)$ and age at menopause $(n=28)$. After these exclusions, a final sample of 1,625 (84.3\% of the eligible sample) participants was included in our analysis. Those excluded due to missing data were more likely to have high education $(92.1 \%$ vs. $89.3 \%)$, but have a comparable median Life's Simple 7 total score [17(15-20) vs. 17(14-20)].

The characteristics of participants are shown in Table 1 . The median age of participants was 60.0 years (25th-75th percentiles: 54.0-65.0 years). The percentage of the women with reproductive risk factors ranged from $7.3 \%$ (with more than three children) to $63.9 \%$ (pregnancy losses). A total of $53.8 \%$ of participants reported one reproductive risk factor; $19.3 \%$ reported two; and $2.1 \%$ reported three or four reproductive risk factors.

Table 1 Characteristics of the postmenopausal women in CSWHSP 2013-2014 without prevalent cardiovascular disease $(N=1625)$

\begin{tabular}{|c|c|}
\hline \multicolumn{2}{|l|}{ Characteristics } \\
\hline Age, median (25th-75th percentiles) years & $60.0(54.0-65.0)$ \\
\hline Education level: college graduate or advanced, n (\%) & $1451(89.3 \%)$ \\
\hline \multicolumn{2}{|l|}{ Individual reproductive risk factors } \\
\hline Earlier age at menarche, $\mathrm{n}(\%)$ & $239(14.7)$ \\
\hline Earlier age at menopause, $\mathrm{n}(\%)$ & 206(12.7) \\
\hline With more than three children, $\mathrm{n}(\%)$ & $119(7.32)$ \\
\hline Pregnancy losses, n (\%) & 1038(63.9) \\
\hline \multicolumn{2}{|l|}{ Number of reproductive risk factors } \\
\hline $0, n(\%)$ & 404(24.9) \\
\hline $1, \mathrm{n}(\%)$ & $874(53.8)$ \\
\hline $2, \mathrm{n}(\%)$ & $313(19.3)$ \\
\hline 3 or $4, n(\%)$ & $34(2.1)$ \\
\hline \multicolumn{2}{|l|}{ Ideal health metrics } \\
\hline $\mathrm{BMI}<25 \mathrm{~kg} / \mathrm{m}^{2}, \mathrm{n}(\%)$ & 1140(70.2) \\
\hline Physical activity $\geq 90$ min/week, n (\%) & $735(45.2)$ \\
\hline Healthy dietary intake, n (\%) & 186(11.4) \\
\hline Never smoker, n (\%) & 1621(99.8) \\
\hline Untreated total cholesterol < 5.17 mmol/L, n (\%) & $671(41.3)$ \\
\hline Untreated blood pressure < 120/80 mm Hg, n (\%) & $539(33.2)$ \\
\hline Untreated fasting blood glucose $<5.6 \mathrm{mmol} / \mathrm{L}, \mathrm{n}(\%)$ & 1093(67.3) \\
\hline \multicolumn{2}{|l|}{ Ideal Life's Simple 7 score categories } \\
\hline $0-1, \mathrm{n}(\%)$ & $56(3.4)$ \\
\hline $2, \mathrm{n}(\%)$ & $235(14.5)$ \\
\hline $3, \mathrm{n}(\%)$ & 433(26.6) \\
\hline $4, \mathrm{n}(\%)$ & $480(29.5)$ \\
\hline $5, n(\%)$ & 298(18.3) \\
\hline $6-7, \mathrm{n}(\%)$ & 123(7.6) \\
\hline Life's Simple 7 score (7-21), median (interquartile range) & $17(14-20)$ \\
\hline
\end{tabular}


Meanwhile $3.4 \%$ of the participants had 0-1 ideal health metrics and $7.6 \%$ of participants had 6-7 ideal health metrics.

After age- adjustment, participants with earlier age at menarche were less likely to have ideal levels of BMI, physical activity, blood pressure, and FBG (Table 2). Participants with earlier age at menopause were less likely to have ideal levels for BMI, physical activity, and FBG (each $P<0.01$ ). Participants with high parity were less likely to have ideal levels for BMI and physical activity but more likely to have ideal levels of cholesterol. Participants with history of pregnancy losses were less likely to have ideal levels for FBG.

Table 3 shows the odds ratios (95\% CIs) of ideal Life's Simple 7 scores for each individual reproductive risk factor after adjustment for age. Participants with earlier age at menarche, earlier age at menopause, high parity, and with history of pregnancy losses, had an increasingly lower odds of obtaining higher ideal Life's Simple 7 scores (all $P<0.05)$.
Table 4 shows odds ratios (95\% CIs) for ideal Life's Simple 7 scores associated with exposure to cumulative reproductive risk after adjustment for age. Participants with a greater number of reproductive risk factors were significantly less likely to have higher ideal Life's Simple 7 scores.

\section{Discussion}

Our results demonstrated that Chinese postmenopausal women who had greater number of reproductive risk factors were less likely to have ideal levels of several components of the American Heart Association's Life's Simple 7. As exposure to the number of reproductive risk factors increased, individuals were less likely to have ideal levels of cardiovascular health behaviors and factors assessed using the Life's Simple 7 metric. These findings highlight the importance of accounting for multiple reproductive risk factors in examining associations between reproductive history and ideal cardiovascular health in women after menopause.

Table 2 Odds ratios for Life's Simple 7 components associated with individual reproductive risk factors among CSWHSP 2013-2014 participants $^{a}$

\begin{tabular}{|c|c|c|c|c|}
\hline \multirow[t]{2}{*}{ Components } & Earlier age at menarche & Earlier age at menopause & With more than three children & Pregnancy losses \\
\hline & Odds ratio $(95 \% \mathrm{Cl})$ & Odds ratio $(95 \% \mathrm{Cl})$ & Odds ratio (95 \% Cl) & Odds ratio $(95 \% \mathrm{Cl})$ \\
\hline \multicolumn{5}{|l|}{ Body mass index } \\
\hline Poor & 1 (Ref.) & 1 (Ref.) & 1 (Ref.) & 1 (Ref.) \\
\hline Intermediate & $0.86(0.72-0.98)$ & $0.89(0.72-1.03)$ & $0.83(0.66-1.02)$ & $0.88(0.76-1.02)$ \\
\hline Ideal & $0.75(0.58-0.88)$ & $0.72(0.64-0.82)$ & $0.76(0.65-0.96)$ & $0.98(0.92-1.20)$ \\
\hline \multicolumn{5}{|l|}{ Physical activity } \\
\hline Poor & 1 (Ref.) & 1 (Ref.) & 1 (Ref.) & 1 (Ref.) \\
\hline Intermediate & $0.62(0.43-0.85)$ & $0.92(0.76-1.03)$ & $0.82(0.74-0.92)$ & $0.92(0.86-1.04)$ \\
\hline Ideal & $0.48(0.36-0.52)$ & $0.82(0.72-0.96)$ & $0.46(0.32-0.56)$ & $1.12(0.96-1.22)$ \\
\hline \multicolumn{5}{|l|}{ Diet } \\
\hline Poor & 1 (Ref.) & 1 (Ref.) & 1 (Ref.) & 1 (Ref.) \\
\hline Intermediate & $1.03(0.89-1.24)$ & $0.86(0.78-0.96)$ & $0.82(0.72-0.96)$ & $0.82(0.72-0.94)$ \\
\hline Ideal & $1.16(1.02-1.34)$ & $0.46(0.16-1.26)$ & $0.39(0.22-1.18)$ & $0.81(0.25-4.38)$ \\
\hline \multicolumn{5}{|l|}{ Total cholesterol } \\
\hline Poor & 1 (Ref.) & 1 (Ref.) & 1 (Ref.) & 1 (Ref.) \\
\hline Intermediate & $0.89(0.72-1.06)$ & $0.95(0.86-1.08)$ & $1.06(0.98-1.22)$ & $0.95(0.83-1.06)$ \\
\hline Ideal & $0.85(0.65-1.02)$ & $1.13(0.96-1.26)$ & $1.18(1.05-1.32)$ & $1.16(0.96-1.24)$ \\
\hline \multicolumn{5}{|l|}{ Blood pressure } \\
\hline Poor & 1 (Ref.) & 1 (Ref.) & 1 (Ref.) & 1 (Ref.) \\
\hline Intermediate & $0.75(0.68-0.88)$ & $0.87(0.72-1.02)$ & $0.86(0.68-0.92)$ & $0.86(0.68-0.92)$ \\
\hline Ideal & $0.72(0.64-0.83)$ & $0.83(0.76-0.95)$ & $0.76(0.70-1.08)$ & $0.94(0.82-1.10)$ \\
\hline \multicolumn{5}{|c|}{ Fasting blood glucose } \\
\hline Poor & 1 (Ref.) & 1 (Ref.) & 1 (Ref.) & 1 (Ref.) \\
\hline Intermediate & $0.76(0.62-0.83)$ & $0.72(0.62-0.88)$ & $0.88(0.62-1.08)$ & $0.72(0.62-0.90)$ \\
\hline Ideal & $0.48(0.43-0.58)$ & $0.32(0.28-0.42)$ & $0.82(0.65-1.02)$ & $0.56(0.48-0.72)$ \\
\hline
\end{tabular}


Table 3 Odds ratios for ideal Life's Simple 7 scores associated with individual reproductive risk factors among CSWHSP 2013-2014 participants $^{\mathrm{a}}$

\begin{tabular}{lllll}
\hline Ideal life's simple 7 scores & $\begin{array}{l}\text { Earlier age at menarche } \\
\text { Odds ratio }(95 \% \mathrm{Cl})\end{array}$ & $\begin{array}{l}\text { Earlier age at menopause } \\
\text { Odds ratio }(95 \% \mathrm{Cl})\end{array}$ & $\begin{array}{l}\text { With more than three children } \\
\text { Odds ratio }(95 \% \mathrm{Cl})\end{array}$ & $\begin{array}{l}\text { Pregnancy losses } \\
\text { Odds ratio (95 \% Cl) }\end{array}$ \\
\hline $0-1$ & 1 (Ref.) & 1 (Ref.) & 1 (Ref.) & 1 (Ref.) \\
2 & $0.66(0.56-0.76)$ & $0.78(0.62-0.82)$ & $0.72(0.62-0.82)$ & $1.02(0.92-1.18)$ \\
3 & $0.62(0.55-0.72)$ & $0.72(0.66-0.86)$ & $0.66(0.58-0.76)$ & $0.96(0.82-1.12)$ \\
4 & $0.58(0.52-0.68)$ & $0.68(0.54-0.72)$ & $0.62(0.52-0.68)$ & $0.92(0.78-1.08)$ \\
5 & $0.46(0.36-0.52)$ & $0.58(0.52-0.66)$ & $0.56(0.48-0.66)$ & $0.82(0.72-0.96)$ \\
$6-7$ & $0.32(0.22-0.38)$ & $0.46(0.32-0.58)$ & $0.42(0.38-0.56)$ & $0.76(0.66-0.92)$ \\
$P$ value & $<0.001$ & $<0.001$ & $<0.001$ & 0.025 \\
\hline
\end{tabular}

${ }^{\mathrm{a} O d d s}$ ratios are adjusted for age

Female-specific factors, primarily using single indicators of reproductive history, have been previously shown to be associated with differences in the presence of CVD risk factors [15-21]. In a population-based cross-sectional study from Korea, Jung et al. demonstrated that women with shorter ovarian hormone exposure defined as duration between menarche and menopause had increased cardiovascular risk [15]. Using data from the Cardiovascular Risk in Young Finns study, Skilton et al. showed that the progression of carotid atherosclerosis over a 6-year period is increased in females who gave birth during the same period, independent of traditional risk factors [20]. Similarly, using population-based cross-sectional data from China, Feng et al. demonstrated that age at menarche, reproductive years, and menopause status were significantly associated with body composition, insulin sensitivity and blood lipid levels [21]. However, reproductive risk factors developing in different stages throughout a woman's life are seldom singular experiences and the present study has demonstrated that cumulative reproductive risk measures may better represent unfavorable reproductive profile than do single indicators. Furthermore, to the best of our knowledge, there are few previous studies on the association of reproductive factors and cardiovascular health metrics. Further cross-ethnic research is needed to clarify whether the

Table 4 Odds ratios for ideal Life's Simple 7 scores associated with cumulative reproductive risk score among CSWHSP 2013-2014 participants ${ }^{\mathrm{a}}$

\begin{tabular}{llll}
\hline Ideal life's simple & \multicolumn{3}{l}{ Number of reproductive risk factors } \\
\cline { 2 - 4 } scores & 1 & 2 & 3 or 4 \\
\hline $0-1$ (Ref.) & 1 (Ref.) & 1 (Ref.) & 1 (Ref.) \\
2 & $0.86(0.76-1.02)$ & $0.74(0.56-0.88)$ & $0.76(0.64-0.92)$ \\
3 & $0.78(0.68-0.96)$ & $0.68(0.58-0.83)$ & $0.72(0.56-0.88)$ \\
4 & $0.72(0.62-0.88)$ & $0.62(0.54-0.76)$ & $0.64(0.52-0.78)$ \\
5 & $0.65(0.48-0.75)$ & $0.42(0.36-0.56)$ & $0.56(0.46-0.68)$ \\
$6-7$ & $0.52(0.42-0.66)$ & $0.22(0.16-0.26)$ & $0.16(0.12-0.22)$ \\
\hline
\end{tabular}

The reference group consists of participants with no reproductive risk factors

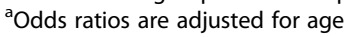

association between cumulative reproductive risk exposure and ideal cardiovascular health is established among women.

This major strength of the study was its relatively large sample paired with first investigation of cumulative reproductive risk and ideal cardiovascular health. However, this study has several limitations. First, cross-sectional nature of the study should be considered when interpreting the findings reported. Second, Selection bias might have occurred because participants were community residents comprising urban women from middle to upper socioeconomic strata who underwent a health screening in a single area of China. Third, since privacy considerations, the reproductive risk profile might be misclassified due to the lack of detailed information about the childbearing history. Thus the current findings are probably underestimates of the true magnitude of the association between cumulative reproductive risk and ideal cardiovascular health. Fourth, we assigned the same weight to the reproductive risk factors in statistical analysis, which may have simplified and misestimated the actual association between the cumulative reproductive risk score and Life's Simple 7 scores. Finally, there also remained a possibility of unmeasured factors or residual confounding might attenuate the strong ORs estimates in this study.

With these strengths and limitations in mind, the present study is the first one to investigate the cumulative effect of reproductive factors on ideal cardiovascular health for Chinese postmenopausal women. Our findings have possible policy implications. It has been identified that endogenous sex hormones have strong links to CVD risk in postmenopausal women [22]. Reproductive history including age at menarche, age at menopause, and gravidity (parity and pregnancy losses) are associated with CVD risk factors, and may best be addressed through primordial prevention. In spite of the progress on evaluating and managing CVD risk in women and the significance of reproductive history in this evaluation [23, 24], gaps in knowledge remain about female-specific risk factors, diagnostic and treatment options that might reduce mortality 
from CVD and improve outcomes for women [25]. One reason for this might be that the history of reproductive events does not play a superior role in the cardiovascular risk profile of postmenopausal women and most of the burden of CVD is by means of the traditional risk factors [24]. Programs that improve current risk assessment strategies by identifying female-specific risk factors during reproductive life, screen women affected by one or more reproductive manifestations of CVD risk, best implement current risk management strategies in these women to offer professional support can be instrumental to prevention of CVD. While this is routinely unappreciated in clinical practice, awareness several reproductive factors can influence ideal cardiovascular health may help clinicians and public health professionals further identify high risk women and thus develop and implement more effective lifestyle management plans [26, 27]. Moreover, since women play influential role in families, motivating midlife women in facing the challenge of adopting healthier behaviors may reap significant and immediate benefits in reducing the risks and consequences of CVD for the health and well being of women and their families [28]. Hence, this issue must be addressed at the government, community and individual levels in order to help them overcome CVD risk and improve their overall health after menopause.

\section{Conclusions}

Findings of this study suggest that achieving ideal levels of several cardiovascular health behaviors and factors was less likely in postmenopausal Chinese women with relative short-term exposure to estrogen. In addition, as the exposure to the number of reproductive risk factors increased, women were increasingly less likely to achieve ideal levels of cardiovascular health after menopause. These findings highlight the need for sufficient resources and appropriate approaches to address multiple reproductive risk exposure among women out the protective effect of estrogen. To evaluate more precisely the effect of the reproductive history on the cardiovascular health for postmenopausal women, large cohort study of postmenopausal women would have to be conducted, using a long follow-up period as well as reliable information regarding the major reproductive factors.

\section{Competing interests}

The authors declare that they have no competing interests.

\section{Authors' contributions}

XC drafted the manuscript, reviewed the literature, analysed and interpreted the data.JSZ participated in the design of the study and performed the statistical analysis. HY analysed and interpreted the data. ZHC acquired the data, analysed and interpreted the data and helped to draft the manuscript. All authors read and approved the final manuscript.

\section{Acknowledgements}

This work was supported in part by a grant from Key Science and Technology Projects in Hunan Province (2014SK3062) and a grant from Science and
Technology Plan Projects (2013BAI04B00). We thank Chang Liu, for his help in programming and statistical analyses as well as all participants for their contribution.

\section{Author details}

'Department of Health Management Center, the Third Xiangya Hospital, Central South University, Tongzipo Road 138, Changsha, Hunan Province 410013, China. ${ }^{2}$ Mental Health Institute, the Second Xiangya Hospital, the Central South University, Changsha, Hunan Province, China. ${ }^{3}$ Department of Clinical Pharmacology Center, the Third Xiangya Hospital, the Central South University, Changsha, Hunan Province, China.

Received: 28 October 2015 Accepted: 16 December 2015

Published online: 21 December 2015

\section{References}

1. Lloyd-Jones DM, Hong Y, Labarthe D, Mozaffarian D, Appel LJ, Van Horn L, et al. Defining and setting national goals for cardiovascular health promotion and disease reduction: the American Heart Association's strategic Impact Goal through 2020 and beyond. Circulation. 2010;121(4):586-613. doi:10.1161/CIRCULATIONAHA.109.192703.

2. Folsom AR, Yatsuya H, Nettleton JA, Lutsey PL, Cushman M, Rosamond WD. Community prevalence of ideal cardiovascular health, by the American Heart Association definition, and relationship with cardiovascular disease incidence. J Am Coll Cardiol. 2011;57(16):1690-6. doi:10.1016/j.jacc.2010.11.041.

3. Xanthakis V, Enserro DM, Murabito JM, Polak JF, Wollert KC, Januzzi JL, et al. Ideal cardiovascular health: associations with biomarkers and subclinical disease and impact on incidence of cardiovascular disease in the Framingham Offspring Study. Circulation. 2014;130(19):1676-83. doi:10.1161/CIRCULATIONAHA.114.009273.

4. Ridker PM, Manson JE, Buring JE, Shih J, Matias M, Hennekens $\mathrm{CH}$. Homocysteine and risk of cardiovascular disease among postmenopausal women. JAMA. 1999;281(19):1817-21. doi:joc81755 [pii].

5. Page JH, Rexrode KM, Hu F, Albert CM, Chae CU, Manson JE. Waist-height ratio as a predictor of coronary heart disease among women. Epidemiology. 2009;20(3):361-6. doi:10.1097/EDE.0b013e31819f38f1.

6. de Kleijn MJ, van der Schouw YT, van der Graaf Y. Reproductive history and cardiovascular disease risk in postmenopausal women: a review of the literature. Maturitas. 1999;33(1):7-36. doi:S0378-5122(99)00038-9 [pii].

7. Chang HS, Odongua N, Ohrr H, Sull JW, Nam CM. Reproductive risk factors for cardiovascular disease mortality among postmenopausal women in Korea: the Kangwha Cohort Study, 1985-2005. Menopause. 2011;18(11):1205-12. doi:10.1097/gme.0b013e31821adb43.

8. Gallagher LG, Davis LB, Ray RM, Psaty BM, Gao DL, Checkoway H, et al. Reproductive history and mortality from cardiovascular disease among women textile workers in Shanghai, China. Int J Epidemiol. 2011;40(6):1510-8. doi:10.1093/ije/dyr134dyr134.

9. Cui R, Iso H, Toyoshima H, Date C, Yamamoto A, Kikuchi S, et al. Relationships of age at menarche and menopause, and reproductive year with mortality from cardiovascular disease in Japanese postmenopausal women: the JACC study. J Epidemiol. 2006;16(5):177-84. JST JSTAGE/jea/16.177.

10. Soules MR, Sherman S, Parrott E, Rebar R, Santoro N, Utian W, et al. Executive summary: Stages of Reproductive Aging Workshop (STRAW) Park City, Utah, July, 2001. Menopause. 2001;8(6):402-7.

11. Charalampopoulos D, McLoughlin A, Elks CE, Ong KK. Age at menarche and risks of all-cause and cardiovascular death: a systematic review and metaanalysis. Am J Epidemiol. 2014;180(1):29-40. doi:10.1093/aje/kwu113kwu113 [pii].

12. Pikwer M, Bergstrom U, Nilsson JA, Jacobsson L, Turesson C. Early menopause is an independent predictor of rheumatoid arthritis. Ann Rheum Dis. 2012;71(3):378-81. doi:10.1136/ard.2011.200059ard.2011.200059 [pii].

13. Ponsonby AL, Lucas RM, van der Mei IA, Dear K, Valery PC, Pender MP, et al. Offspring number, pregnancy, and risk of a first clinical demyelinating event the Auslmmune Study. Neurology. 2012;78(12):867-74. doi:10.1212/WNL. Ob013e31824c4648WNL.0b013e31824c4648 [pii].

14. Ranthe MF, Andersen EA, Wohlfahrt J, Bundgaard H, Melbye M, Boyd HA. Pregnancy loss and later risk of atherosclerotic disease. Circulation. 2013;127(17):1775-82. doi:10.1161/CIRCULATIONAHA.112.000285. CIRCULATIONAHA.112.000285 [pii].

15. Jung KJ, Kim MR, Yun YD, Kim HC, Jee SH. Duration of ovarian hormone exposure and atherosclerotic cardiovascular disease in Korean women: the Korean Heart Study. Menopause. 2015. doi:10.1097/GME.0000000000000489. 
16. Roeters van Lennep JE, Heida KY, Bots ML, Hoek A. Cardiovascular disease risk in women with premature ovarian insufficiency: A systematic review and meta-analysis. Eur J Prev Cardiol. 2014. doi:10.1177/2047487314556004.

17. Parker DR, Lu B, Sands-Lincoln M, Kroenke CH, Lee CC, O'Sullivan M, et al. Risk of cardiovascular disease among postmenopausal women with prior pregnancy loss: the women's health initiative. Ann Fam Med. 2014;12(4):302-9. doi:10.1370/afm.166812/4/302

18. Knipe DW, Fraser A, Lawlor DA, Howe LD. Is interpregnancy interval associated with cardiovascular risk factors in later life? A cohort study. BMJ Open 2014;4(3):e004173. doi:10.1136/bmjopen-2013-004173bmjopen-2013-004173.

19. Cagnacci A, Cannoletta M, Palma F, Zanin R, Xholli A, Volpe A. Menopausal symptoms and risk factors for cardiovascular disease in postmenopause. Climacteric. 2012;15(2):157-62. doi:10.3109/13697137.2011.617852.

20. Skilton MR, Bonnet F, Begg LM, Juonala M, Kahonen M, Lehtimaki T, et al. Childbearing, child-rearing, cardiovascular risk factors, and progression of carotid intima-media thickness: the Cardiovascular Risk in Young Finns study. Stroke. 2010;41(7):1332-7. doi:10.1161/STROKEAHA.110.579219. STROKEAHA. 110.579219 [pii].

21. Feng $Y$, Hong $X$, Wilker $E, L i Z$, Zhang $W$, Jin $D$, et al. Effects of age at menarche, reproductive years, and menopause on metabolic risk factors for cardiovascular diseases. Atherosclerosis. 2008;196(2):590-7. doi:10.1016/j. atherosclerosis.2007.06.016.

22. Guducu N, Gormus U, Kutay SS, Kavak ZN, Telatar B. Endogenous sex hormones and their associations with cardiovascular risk factors in postmenopausal women. J Endocrinol Invest. 2013;36(8):588-92. doi:10.3275/8881. 8881 [pii].

23. Ley SH, Li Y, Tobias DK, Manson JE, Hu FB, Rexrode KM. Reproductive Lifespan and Risk of Cardiovascular Disease (CVD) in Women. Circulation. 2014;130 Suppl 2:A12098-A.

24. van der Meer MG, van der Graaf $Y$, Schuit E, Verschuren W, Boer JM, Peelen LM, et al. The Added Value of Female-Specific Risk Factors on Top of the Framingham Risk Score for the Prediction of Cardiovascular Disease in Women: Data From EPIC-NL. Circulation. 2014;130 Suppl 2:A15715-A.

25. Harvey RE, Coffman KE, Miller VM. Women-specific factors to consider in risk, diagnosis and treatment of cardiovascular disease. Womens Health (Lond Engl). 2015;11(2):239-57. doi:10.2217/whe.14.64.

26. Appelman Y, van Rijn BB, Ten Haaf ME, Boersma E, Peters SA. Sex differences in cardiovascular risk factors and disease prevention. Atherosclerosis. 2015;241(1):211-8. doi:10.1016/j.atherosclerosis.2015.01.027.

27. Choo J, Lee J, Cho JH, Burke LE, Sekikawa A, Jae SY. Effects of weight management by exercise modes on markers of subclinical atherosclerosis and cardiometabolic profile among women with abdominal obesity: a randomized controlled trial. BMC Cardiovasc Disord. 2014;14:82. doi:10.1186/1471-2261-14-82.

28. Organization WH. Women and health: today's evidence tomorrow's agenda. Geneva: World Health Organization; 2009

\section{Submit your next manuscript to BioMed Central and we will help you at every step:}

- We accept pre-submission inquiries

- Our selector tool helps you to find the most relevant journal

- We provide round the clock customer support

- Convenient online submission

- Thorough peer review

- Inclusion in PubMed and all major indexing services

- Maximum visibility for your research

Submit your manuscript at www.biomedcentral.com/submit 